\title{
Sociological and psychological predictors of STD infection in homosexual men:
}

\section{A study of four countries}

\author{
MICHAEL W ROSS \\ From the Department of Psychiatry, The Flinders University of South Australia Medical School, Bedford \\ Park, Australia
}

SUMMARY I investigated over 600 homosexual men in four countries (Sweden, Finland, Ireland, and Australia) regarding the number of times they had contracted a sexually transmitted disease (STD) and several psychological variables including masculinity and feminity, sex role conservatism, relationships with parents, number of sexual partners, attitudes towards homosexuality, and involvement in the homosexual subculture. Using multiple linear regression in each country, it was found that $19-42 \%$ of the variance of number of times infected could be accounted for by psychosocial factors, seven of which were common to all countries. The number of sexual partners was not a significant variable in any country. These data strongly suggest that numbers of infections in homosexual men are best predicted by psychological factors, and this has considerable implications for preventative and treatment programmes for homosexuals.

\section{Introduction}

Much information on sociological concommitants of sexually transmitted diseases in numerous populations has been published. Such variables as socioeconomic status, race, religion, education, and gender have all been examined in relation to differences in rates of infection with sexually tranmitted disease (STD) in various populations. Most of such data, however, are derived from STD clinic attenders, and cannot differentiate between members of those groups who may attend clinics in disproportionate numbers. As a consequence, little has been written on group characteristics which predict STD infection, and generally as little on psychological factors, although Hart has commented that one must consider STD to be "a behavioural problem, the control of which requires focus on the fundamental personality of the individual". ${ }^{1}$

Psychological factors which have previously been identified with high STD infection rates include extraversion (in heterosexuals) and in some people a higher degree of neuroticism as well. Several studies, have also implicated child rearing patterns, with

Address for reprints: Dr M W Ross, Department of Psychiatry, The Flinders University of South Australia Medical Schooi, Bedford Park, S A 5042, Australia

Accepted for publication 13 September 1983 families of four or more children producing a higher proportion of those infected. ${ }^{2} 3$ Studies which have looked at sexual problems in those attending STD clinics have noted that between one fifth and one quarter of those presenting were experiencing sexual dysfunction, for which they would have liked further help. ${ }^{4}$

Social as well as psychological factors must be taken into account, and Ross found that such variables as sex role rigidity and the antihomosexual stance of a society may influence incidence of STD in homosexual men. ${ }^{5}$ Hart noted, however, that the tendency to generalise about STD patients by building a composite picture from participants in widely differing environments confuses the issue, especially with regard to social and psychological factors. ${ }^{6}$ Thus what holds for heterosexuals may well not hold for homosexuals, or between sexes or races. It is therefore necessary to concentrate on a relatively homogeneous group in examining psychological predictors of STD infections.

This study investigated male homosexuals with regard to both social and psychological determinants of STD infection, although as Hart has indicated some social variables may be secondary in that all are primarily related to the personality of the individual. ${ }^{2}$ To determine common elements between cultures I studied homosexuals in four Western societies. 


\section{Subjects and methods}

The subjects were those reported on in a previous study which looked at STD in homosexual men in four societies. ${ }^{7}$ The study population consisted of 176 Swedish, 158 Australian, 149 Finnish, and 121 Irish homosexual men (604 respondents in total), whose characteristics are given in table $I$.

Questionnaires, complete with stamped addressed envelopes for return, were given to homosexual rights and social clubs in Stockholm, Melbourne and Brisbane, Helsinki, and Dublin. Each club was the main homosexual or social rights organisation in that city, and the aims and functions of the five clubs selected appeared to be almost identical. The response rate was $46.6 \%$ in Stockholm, $44 \%$ in Melbourne and Brisbane, $54 \%$ in Helsinki and $48.6 \%$ in Dublin. This response rate was based on the number of questionnaires given to each club (one for each member on its mailing list).

\section{QUESTIONNAIRE}

The questions asked were part of an anonymous wider questionnaire comparing lifestyles of homosexual men in Sweden, Australia, Finland, and Ireland. Respondents were asked whether they had had gonorrhoea, syphilis, or any other STD (they could specify which) and the number of times they had had each. Other variables investigated included sex roles as measured by the Bem sex role inventory (BSRI), ${ }^{8}$ which measures masculinity and feminity as separate dimensions, the sex role survey (SRS) measure of sex role conservatism, ${ }^{9}$ and a number of demographic variables including age, age at which respondents realised they were homosexual, age of becoming homosexually active, years of education, social class of parents, religious commitment, expected and actual social reaction to homosexuality, ${ }^{10}$ position on the Kinsey Scale, how well the respondent had related to his mother and father (measured on an eight point scale ranging between "well" and "not at all well"), average number of partners per month over the past year, whether the respondent had ever been in a homosexual relationship for over two years, and the proportion of people who knew the respondent was homosexual. Ten questionnaires from each sample in which respondents identified themselves were subsequently compared with interviews with the men as a check on accuracy, and no discrepancies were found. Swedish questionnaires were translated into Swedish by two people and checked for accuracy by a third; translation of the Finnish questionnaire followed a similar procedure. Questionnaires in Australia and Ireland were in English.

\section{ANALYSIS}

Data were analysed separately for each country. Multiple linear regressions were performed on the data with forward inclusion criteria of $p=0.5$ on the basis of the exploratory nature of the data. Variables included were those described in the questionnaire, with the dependent variable being the total number of infections for syphilis, gonorrhoea, or any other STD.

\section{Results}

Results are presented in tables I and II. Differences between study populations should not systematically affect results, as distribution was essentially random. Given the substantial similarities between populations and the large number of subjects, however, these data suggest that the four groups were reasonably well matched.

TABLE I Mean (SD) characteristics of homosexuals in four countries

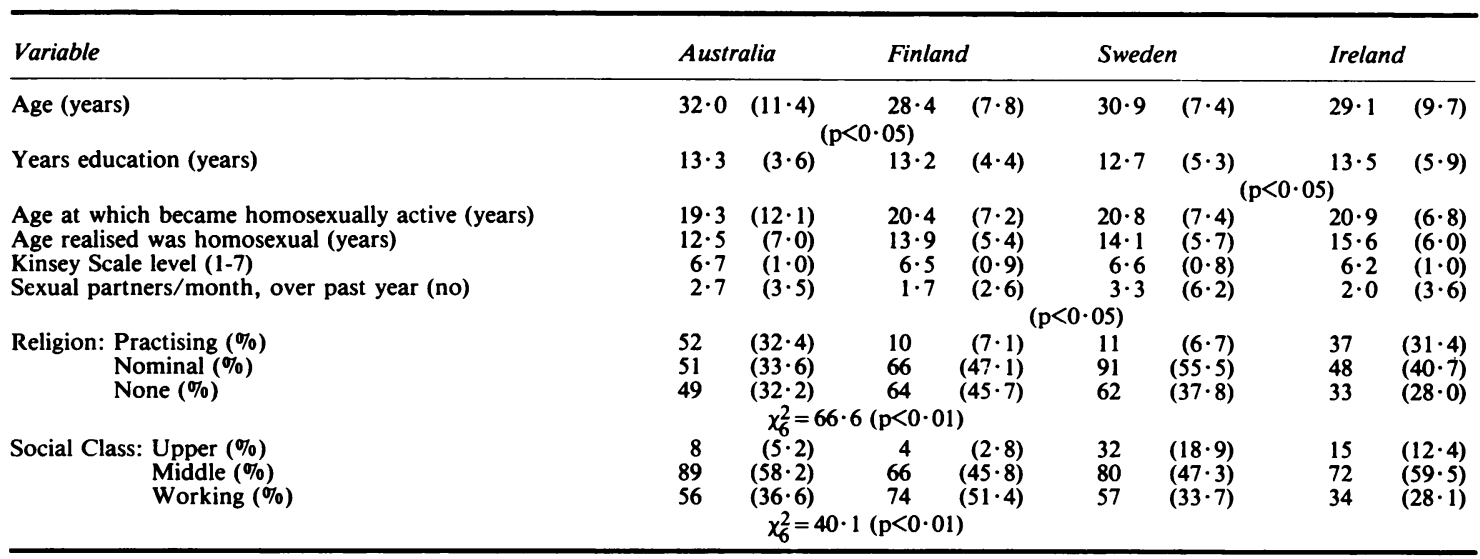


TABLE II Predictors of infection in homosexual men in four countries

\begin{tabular}{|c|c|c|c|}
\hline & $\boldsymbol{B}$ & Beta & Cumulative $R^{2}$ \\
\hline $\begin{array}{l}\text { Sweden } \\
\text { Masculinity } \\
\text { Expected social reaction to homosexuality } \\
\text { Time since became homosexually active } \\
\text { Femininity } \\
\text { Social class } \\
\text { Age became homosexually active } \\
\text { Actual social reaction to homosexuality }\end{array}$ & $\begin{array}{r}0.225 \\
0.007 \\
0.125 \\
-0.156 \\
-0.796 \\
-0.086 \\
0.004\end{array}$ & $\begin{array}{r}0.452 \\
0 \cdot 300 \\
0 \cdot 289 \\
-0 \cdot 220 \\
-0 \cdot 189 \\
-0 \cdot 157 \\
0 \cdot 147\end{array}$ & $\begin{array}{l}0 \cdot 141^{* * *} \\
0 \cdot 210^{* * *} \\
0 \cdot 282^{* * *} \\
0 \cdot 319^{* * *} \\
0 \cdot 350^{* *} \\
0 \cdot 371^{*} \\
0 \cdot 391^{*}\end{array}$ \\
\hline $\begin{array}{l}\text { Australia } \\
\text { Femininity } \\
\text { Time since became homosexually active } \\
\text { Sex role conservatism } \\
\text { Religious commitment } \\
\text { Time spent in homosexual subculture } \\
\text { Relationship with father }\end{array}$ & $\begin{array}{r}-0.129 \\
0.079 \\
-0.054 \\
0.478 \\
0.239 \\
-0.136\end{array}$ & $\begin{array}{r}-0.247 \\
0.322 \\
0.319 \\
0 \cdot 178 \\
0.158 \\
-0 \cdot 152\end{array}$ & $\begin{array}{l}0 \cdot 054^{* * *} \\
0 \cdot 103^{* * *} \\
0 \cdot 176^{* * *} \\
0 \cdot 207^{* *} \\
0 \cdot 234^{*} \\
0 \cdot 254^{*}\end{array}$ \\
\hline $\begin{array}{l}\text { Finland } \\
\text { Time since became homosexually active } \\
\text { Age realised was homosexual } \\
\text { Sex role conservatism } \\
\text { Religious commitment }\end{array}$ & $\begin{array}{l}0.063 \\
0.052 \\
0.025 \\
0.333\end{array}$ & $\begin{array}{l}0 \cdot 443 \\
0 \cdot 341 \\
0 \cdot 258 \\
0 \cdot 169\end{array}$ & $\begin{array}{l}0 \cdot 054^{* * *} \\
0 \cdot 120^{* * *} \\
0 \cdot 162^{* * *} \\
0 \cdot 187^{*}\end{array}$ \\
\hline $\begin{array}{l}\text { Ireland } \\
\text { Homosexual relationship }>2 \text { years } \\
\text { Time spent in homosexual subculture } \\
\text { Relationship with father } \\
\text { Femininity } \\
\text { Attitudes toward homosexuality } \\
\text { Position on Kinsey Scale }\end{array}$ & $\begin{array}{r}-1 \cdot 311 \\
0.463 \\
-0.208 \\
-0.064 \\
-0.037 \\
-0.355\end{array}$ & $\begin{array}{r}-0.454 \\
0.465 \\
-0.309 \\
-0.235 \\
-0.206 \\
-0.188\end{array}$ & $\begin{array}{l}0 \cdot 120^{* * *} \\
0 \cdot 251^{* * *} \\
0 \cdot 302^{* * *} \\
0 \cdot 353^{* * *} \\
0 \cdot 386^{* *} \\
0 \cdot 419^{* *}\end{array}$ \\
\hline
\end{tabular}

${ }^{*} \mathrm{p}<0.1 ;{ }^{* *} \mathrm{p}<0.05 ;{ }^{* * *} \mathrm{p}<0.01$.

\section{Discussion}

From table II it can be seen that between four and seven variables significantly predicted the number of times men in each country were infected. These variables were able to predict between $18 \cdot 7 \%$ (Finland) and $41.9 \%$ (Ireland) of the variance of times infected, a fairly major proportion considering that social and psychological factors were being investigated. Seven of the variables predicted infections in more than one country.

Of particular interest are those variables which were common to more than one country: sex role (masculinity and femininity), sex role conservatism, religious commitment, time since the respondent became homosexually active, the amount of leisure time spent in the homosexual subculture, and relationship with the father. In all countries all variables except sex role conservatism related in the same direction. Masculinity (defined as a dominant, controlling personality) was associated with more infections, and femininity (defined as a passive, unassertive personality) with fewer infections. Sex role conservatism was associated with a higher rate of infection in Finland and a lower one in Australia. This measured the degree to which respondents felt that women and men should have equality in a number of areas, and in Finland this was associated with a higher rate of infection through increased masculine and assertive behaviour, whereas in Australia the more feminist homosexual men had higher infection rates. Greater religious commitment in each case led to lower infection rates, which confirms findings in previous research. Also in line with previous findings was the fact that both the length of time since becoming homosexually active (and hence a longer time in which STD might have been contracted) and the amount of time spent in the homosexual subculture (probably reflecting involvement in the subculture and the importance of a homosexual identity to the individual) were associated with increased infection rates.

The association of the relationship with the father and number of times infected is also of interest. These data indicated that a bad relationship with the father was likely to lead to more infections. The psychodynamic implications are interesting, and might show an attempt to come to terms with paternal rejection by making increasing numbers of male sexual contacts to achieve acceptance by other men. At this stage, however, this interpretation is tentative and will clearly require further research.

The variables which were not significantly associated with increased infection were: age, education, and degree of openness about homosexuality. A number of other variables were associated with rate of infection in one country but not others, including expected and actual societal 
reactions to homosexuality, the age at which the man realised he was homosexual, degree of homosexuality, attitudes to homosexuality, and (particularly in Ireland) whether the man had been in a homosexual relationship for two years or more. The variation between countries in predictors does strongly suggest that social factors have some influence on the expression of psychological variables.

Nevertheless, the high degree of similarity between the study populations implicates psychological factors as well as more mechanical relations to infection with STD, such as time spent in the homosexual subculture and length of time since becoming homosexually active. The pervasiveness of predictive variables such as social sex role, sex role conservatism, and relationship with father, all confirm that the psychological dimension of STD infection in homosexual men may be at least as important as demographic variables, if not more so. Whether such psychological factors operate by increasing numbers of partners or the type of partner who is most likely to be infected is not clear. Number of partners was not a major variable, which suggests that STD infection in homosexual men is not simply related to number of partners as a risk factor.

Implicaticns for future research and treatment of homosexually acquired STD are of some importance... These data suggest that it may be possible to modify some of the variables predictive of increased numbers of infections. If such variables are also precursors of multiple infections, as these data suggest, then avenues for modification of some of them through health education, modification of attitudes, or by helping individuals come to terms with such factors as attitudes towards parents, may need to be taken into account in treatment and prevention programmes.

Psychological and social factors have a strong and apparently consistent influence on the number of times homosexual men are infected with STD, and it is important to understand their relation to treatment or prevention. Further research is clearly required, however, before such relations can be fully understood.

\section{References}

1. Hart G. Social aspects of venereal disease. II Relationship of personality to other sociological determinants of venereal diseases. Br J Vener Dis 1973; 49:548-52.

2. Hart G. Sexual Maladjustment and Disease. Chicago: NelsonHall, 1977.

3. Singh K, Mohamed E, Sukhija CL. Psychological background of servicemen contracting venereal diseases. $J$ Indian Med Assoc 1966; 46:270-5.

4. Catalan J, Bradley M, Gallwey J, Hawton K. Sexual dysfunction and psychiatric morbidity in patients attending a clinic for sexually transmitted diseases. $B r J$ Psychiatry 1981; 138: $292-6$.

5. Ross MW. Social factors in homosexually acquired venereal diseases: comparison between Sweden and Australia. $\mathrm{Br} J$ Vener Dis 1982; 58:263-8.

6. Hart G. Social aspects of venereal disease. I Sociological determinants of venereal disease. Br J Vener Dis 1973; 49:542-7.

7. Ross MW. Sexually transmitted diseases in homosexual men: a study of four societies. Br J Vener Dis 1984; 60:52-5.

8. Bem SL. The measurement of psychological androgyny. $J$ Consult Clin Psychol 1974; 42:155-62.

9. MacDonald AP. Identification and measurement of multidimensional attitudes towards equality between the sexes. J Homosex 1974; 1: 165-82.

10. Ross MW. Societal reaction, adjustment and homosexuality: measurement in two societies. Journal of Sex Research, (in press). 